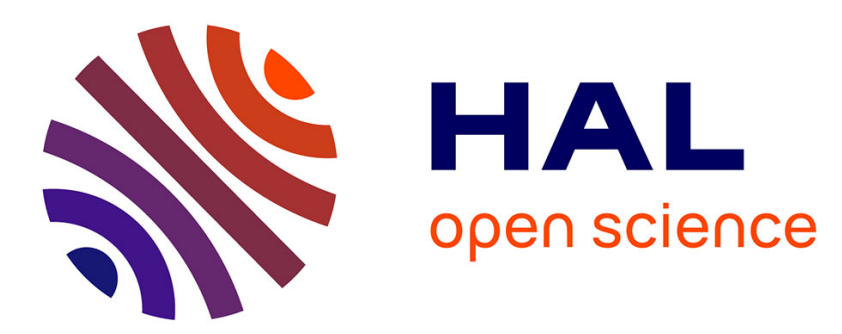

\title{
Direct glutamate-mediated presynaptic inhibition of sensory afferents by the postsynaptic motor neurons
}

Daniel Cattaert, Didier Le Ray

\section{To cite this version:}

Daniel Cattaert, Didier Le Ray. Direct glutamate-mediated presynaptic inhibition of sensory afferents by the postsynaptic motor neurons. European Journal of Neuroscience, 1998, 10, pp.3737 - 3746. 10.1046/j.1460-9568.1998.00384.x . hal-02346679

\section{HAL Id: hal-02346679 \\ https://hal.science/hal-02346679}

Submitted on 7 Nov 2019

HAL is a multi-disciplinary open access archive for the deposit and dissemination of scientific research documents, whether they are published or not. The documents may come from teaching and research institutions in France or abroad, or from public or private research centers.
L'archive ouverte pluridisciplinaire HAL, est destinée au dépôt et à la diffusion de documents scientifiques de niveau recherche, publiés ou non, émanant des établissements d'enseignement et de recherche français ou étrangers, des laboratoires publics ou privés. 


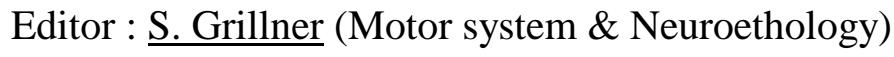

\section{Direct glutamate-mediated presynaptic inhibition}

of sensory afferents by the postsynaptic motor neurons.

CAtTAert DAniel and Le RAy DiDier

Running title : Glutamate-mediated presynaptic inhibition

Keywords : gain control; locomotion; monosynaptic

Total numbers : 30 pages, 9 figures, 1 table.

Corresponding author : Cattaert Daniel

Address : Laboratoire de Neurobiologie et Mouvements, CNRS, 31 chemin J. Aiguier 13402 Marseille cedex 20, France.

Tel : +33 (0) 4.91.16.43.45

Fax :+33 (0) 4.91.77.50.84

e-mail : cattaert@lnf.cnrs-mrs.fr 


\begin{abstract}
An in vitro preparation of the crayfish central nervous system was used to study a negative feedback control exerted by the glutamatergic motor neurons (MNs) onto their presynaptic sensory afferents. This negative control consists in small amplitude, slowly developing depolarizations of the primary afferents (sdPADs) strictly timed with MN bursts. They were not blocked by picrotoxin, but were sensitive to glutamate non-NMDA antagonists. Intracellular recordings were performed within thin branches of sensory terminals while electrical antidromic stimulation were applied to the motor nerves, or while glutamate (the MN neurotransmitter) was pressure-applied close to the recording site. Electrical motor nerve stimulations and glutamate pressure application had similar effects onto sensory terminals issued from the coxo-basipodite chordotonal organ (CBTs) : like sdPADs, both stimulation-induced depolarizations were picrotoxin-resistant and were dramatically reduced by non-NMDA antagonist bath-application. These results indicate that sdPADs are likely directly produced by MNs during locomotor activity. A functional scheme is proposed.
\end{abstract}

\title{
Introduction
}

Since the discovery of presynaptic inhibition (Dudel and Kuffler, 1961; Frank and Fuortes, 1957), synaptic efficacy has no longer been considered as immovable and recent studies have described an increasing number of presynaptic control mechanisms. Today, presynaptic inhibition appears to be a widespread phenomenon, largely exploited by nervous systems to select afferent informations during the performing of specific movements (Cattaert et al., 1992; Grillner et al., 1991; Rudomin et al., 1998). Extensively studied (for reviews, see Rudomin et al., 1998 and Clarac and Cattaert, 1996), presynaptic inhibition has been found to share common features in both vertebrate and invertebrate models. The most commonly described inhibitory mechanism was first demonstrated by Eccles et al. $(1962,1963)$ in cat 
spinal cord and confirmed by numerous authors in other species (Burrows and Laurent, 1993; Cattaert et al., 1992; Christenson and Grillner, 1991; Christenson et al., 1991; Davidoff, 1972; El Manira and Clarac, 1991). It involves the inhibitory neurotransmitter $\gamma$-aminobutyric acid (GABA) which provokes depolarizations in the sensory terminals (therefore termed primary afferent depolarizations : PADs), that have been found to result from a strong increase in chloride conductance, and to induce the shunt of the afferent spikes. However, recent studies demonstrated that GABA was not the only neurotransmitter capable of producing effective presynaptic inhibition. In vertebrates, monoamines such as acetylcholine, noradrenaline or serotonin have been found to control efficiently the afferent signals (Seybold, 1986; Singer et al., 1996). In the same way, metenkephalin acting through $\mu$-opioid receptors has been demonstrated to reduce strongly the amplitude of the monosynaptic responses evoked by the stimulation of small diameter primary afferents in the dorsal horn of the rat (Hori et al., 1992). Invertebrate models also possess a wide range of neurotransmitters, other than GABA, that are capable of presynaptically filtering the incoming sensory signals : for example, histamine performs such presynaptic inhibitory control in the abdominal ganglia interneurons of Aplysia (Kretz et al., 1986) or in crayfish mechano-sensory afferents (El Manira and Clarac, 1994). In both vertebrates and invertebrates, presynaptic inhibition can originate from various central (Cattaert et al., 1992; Kennedy et al., 1974) or peripheral (Burrows and Laurent, 1993; Marchand et al., 1997; Rudomin, 1990) sources. The idea that some GABA-mediated PADs could be triggered by the central pattern generator was proposed because such PADs have been found to be strictly related with the centrally generated locomotor rhythm (Cattaert et al., 1992; Gossard et al., 1989). Recent investigations demonstrating the increasing role of motor neurons (MNs) in the locomotor network of crayfish (Cattaert et al., 1994; Chrachri and Clarac, 1990; Pearlstein et al., 1998), suggest that these MNs are part of the central pattern generator for locomotion. In this report, we present a new mechanism of presynaptic 
inhibition of the primary afferent signals which originates directly from the MNs, and may involve a kainate-like form of glutamate receptor.

\section{Materials and Methods}

Results are based on 73 intracellular recordings from sensory terminals performed on adult male and female crayfish, Procambarus clarkii. Animals were maintained in aquarium at 17$18^{\circ} \mathrm{C}$ and fed once a week.

The in vitro preparation (Chrachri and Clarac, 1990) consisted in the last three thoracic ganglia, and the motor nerves innervating the antagonistic muscles of each of the two proximal joints of the $5^{\text {th }}$ leg : promotor/remotor (Pro/Rem) and depressor/levators (Dep/Lev). The CBCO, that encodes the vertical movements of the leg, was dissected out together with its sensory nerve which projects within the ipsilateral hemi-ganglion. The preparation was then pinned down dorsal side up in a Sylgard-lined Petri dish and superfused with oxygenated crayfish saline ( $\mathrm{NaCl}: 195 \mathrm{mM}, \mathrm{KCl}: 5 \mathrm{mM}, \mathrm{CaCl}_{2}: 13 \mathrm{mM}, \mathrm{MgCl}_{2}: 2 \mathrm{mM}$ ) buffered with $3 \mathrm{mM}$ Hepes and $\mathrm{pH}$ adjusted at 7.7 at $15^{\circ} \mathrm{C}$.

In most experiments, divalent cation concentration was raised $\left(\mathrm{CaCl}_{2}: 34 \mathrm{mM}, \mathrm{MgCl}_{2}\right.$ : $6.4 \mathrm{mM}$ ) with the sodium concentration reduced accordingly, in order to drastically reduce the part of polysynaptic pathways (Berry and Pentreath, 1976). A saline with a very low chloride concentration ( $\mathrm{NaCl}$ replaced by sodium-isothionate), a saline with half-potassium concentration, a half-sodium concentration saline ( $\mathrm{NaCl}$ accordingly replaced by sucrose) or a calcium-free/high magnesium saline $\left(\mathrm{MgCl}_{2}\right.$ being 6-time increased) were used to study the ionic mechanisms of the recorded responses. All saline solutions were buffered with $3 \mathrm{mM}$ Hepes and $\mathrm{pH}$ adjusted at 7.7 at $15^{\circ} \mathrm{C}$ (El Manira et al., 1991). 
Glutamate or kainate was pressure-ejected through a thin glass micro-pipette using a Picospritzer II (General Valve Corporation, Fairfield, NJ). In experiments where glutamate and $\gamma$-amino-butyric acid (GABA) responses were compared (Fig. 6), both neurotransmitters were locally pressure applied using a double-barreled micro-pipette (Marchand and Pearlstein, 1995). All chemicals used were from Sigma (Saint Quentin, Fallavier, France).

Extracellular recordings and nerve stimulations were performed using platinum electrodes contacting the nerves, isolated from bath with petroleum jelly (Vaseline), and signals were amplified by a 4-channel differential amplifier (A-M System, Inc., Everett, WA). Intracellular recordings of the sensory terminals issued from the CBCO (CBTs) were made with thin-walled glass micro-electrodes filled with a potassium chloride solution (3M) and having a 25-30 M $\Omega$ resistance. The signals were amplified by an Axoclamp 2B (Axon Instruments, Inc., Foster City, CA). Intracellular current pulses and nerve stimulations were controlled by a 8 channel digital stimulator (A.M.P.I., Jerusalem, Israel). All signals were monitored on a 4-channel digital oscilloscope (Yokogawa DL 1200, Tokyo, Japan) and stored on a digital tape recorder (BioLogics, DTR 1802, Claix, France), and digitized on PC-based computer through an A/D interface (from Cambridge Electronic Design, CED 1401PLUS, Cambridge, UK). Intracellular and extracellular recordings were digitized at 5-10 kHz and written to disk. Signals were analyzed using the CED programs Spike2 for Windows. Statistical analyses and linear regressions were performed by the GraphPad Prism program (GraphPad Software, Inc., San Diego, CA).

\section{RESULTS}

CBTs display slowly developing PADs related to motor bursts.

Intracellular recordings performed on CBTs during fictive locomotion revealed the existence of small depolarizing events, that could be related clearly to the firing activity of one 
of the proximal motor nerves. In the example presented in Figure 1, rhythmic motor activities were induced by superfusion of the muscarinic cholinergic agonist oxotremorine $\left(10^{-5} \mathrm{M}\right)$. In phase with the levator nerve bursts, the intracellularly recorded CBT displayed small amplitude $(3 \pm 1 \mathrm{mV}$; mean \pm SEM) slowly developing PADs (sdPADs). In contrast, classical GABAergic PADs presented larger amplitudes $(9 \pm 4 \mathrm{mV}$; mean \pm SEM) and were produced at the transition between depressor and levator bursts. However, the GABAergic PADs are not strictly related to the motor cycle (only two bursts occurred during the four cycles shown in Figure 1); whereas a very strict relationship exists between the time course of sdPADs and the instantaneous frequency of discharge within the levator nerve (Lev n Inst. Freq.; Fig. 1). These observations suggest that, during locomotor activity, afferent $\mathrm{CBCO}$ signals are exposed to two sources of presynaptic control, and that motor neurons are able to exert specifically a feedback control onto some of the afferents.

To test the hypothesis that sdPADs and PADs have different origins, and involve different mechanisms, the preparation was superfused with picrotoxin, the blocker of the chloride channel associated to the GABA receptor in crayfish (Cattaert et al., 1992). When the preparation was superfused with picrotoxin $\left(10^{-4} \mathrm{M}\right)$, all reciprocal inhibitory relationships were blocked between antagonistic motor neurons, and synchronized discharges were recorded from all motor nerves (Fig. 2A). In such conditions, the large GABA-mediated PADs completely disappeared from the recorded CBT while the sdPADs summated in larger depolarizations $(4 \pm 2 \mathrm{mV}$; mean $\pm \mathrm{SEM})$ that were produced in phase with the synchronized motor activities (Fig. 2A). On the other hand, as glutamate is the excitatory neurotransmitter used by MNs in crayfish (Van Harreveld, 1980), we investigated the possible role of glutamate in the development of the sdPADs. When a mixture of 6-cyano-7-dinitroquinoxaline-2,3-dione $\left(\mathrm{CNQX}, \quad 10^{-3} \mathrm{M}\right)$ and 6,7-dinitroquinoxaline-2,3-dione (DNQX, $10^{-3} \mathrm{M}$ ), two glutamate antagonists, were added to 
the picrotoxin perfusion, the amplitude of the sdPADs was significantly reduced (see histogram in Fig. 2A; p $<0.05)$. A slight recovery of sdPADs amplitude was observed after removing the mixture of non-NMDA (N-methyl-D-aspartate) glutamate antagonists from the picrotoxin-bath. These results indicate that the sdPADs were likely mediated by glutamate.

In order to test further if sdPADs were produced by MNs, we performed antidromic stimulation of the motor nerves that innervate the proximal muscles of the leg, while intracellularly recording the response in a CBT. As shown in Figure $2 \mathrm{~B}$ (top trace), an electrical stimulation applied to the anterior levator motor nerve was able to elicit a $1-2 \mathrm{mV}$ depolarizing response in the intracellularly recorded CBT. Perfusing the glutamate non-NMDA antagonist DNQX $\left(10^{-3} \mathrm{M}\right)$ induced a 30-50 \%-reduction of the response recorded from the CBT (middle trace). This effect was reversible (bottom trace; each trace is the average of 30 raw data). A similar reduction of the response could be observed during superfusion of CNQX $\left(10^{-3} \mathrm{M}\right.$; data not shown). In the same CBT, comparable results were obtained by applying antidromic stimulation to the depressor nerve (not shown). All CBTs did not respond to the stimulation of motor nerves, and when they did, most of them responded only to the stimulation of one proximal motor nerve. Table 1 summarizes the results obtained from 17 distinct intracellularly recorded CBTs. Although a CBT generally presented a specificity for one motor nerve, some terminals displayed nevertheless depolarizing responses for several antidromically stimulated motor nerves (from 2 to 4). Thus, it appears that crayfish MNs are able to exert directly a glutamate-mediated presynaptic control of their input synapses.

Glutamate- and GABA-induced responses involve distinct mechanisms.

In order to study the properties of the glutamate-mediated sdPADs, we performed direct micro-application of glutamate $\left(10^{-2} \mathrm{M}\right)$ within the neuropile. Micro-ejection of 
glutamate in the vicinity of the small end branches of the CBTs (Fig. 3A) generally evoked a slow depolarizing response in the recorded sensory terminal (Fig. 3B). The reversal potential of the response to glutamate ejection was investigated by measuring the amplitude of the response at various membrane potentials imposed by continuous current injection (Fig. 3C). The response of CBTs varied almost linearly with the imposed membrane potential. It reversed at $-55 \pm 2 \mathrm{mV}$, suggesting the involvement of a composite current.

The response to glutamate micro-application is inhibitory (Fig. 4). When the recorded CBT displayed spontaneous spikes, or when the CBCO nerve was stimulated in order to record orthodromic spike from the CBT (Fig. 4A), the glutamate-induced depolarizing response was accompanied by the decrease of the CBT spike amplitude (mean decrease of about $20 \%$ ) that lasted throughout the depolarization developed (see inset in Fig. 4A). During the glutamate-induced depolarization, the membrane input resistance, measured by injecting hyperpolarizing current pulses within the recorded CBT, was strongly reduced (50-85\%; Fig. 4B). The change of input resistance observed during the glutamate-induced response was not voltage-dependent, because when the resting membrane potential of the recorded CBT was maintained above $-50 \mathrm{mV}$ by continuous current injection, the response reversed into a hyperpolarizing response without modifying the input resistance variation rate (Fig. 4B).

The depolarizing response to glutamate micro-ejection was unaffected by tetrodotoxin $\left(5.10^{-7} \mathrm{M}\right)$ added to the perfusion saline (Fig. 5B, compared to control in Fig. 5A), indicating that glutamate acted directly on the recorded CBT. When picrotoxin $\left(2.10^{-4} \mathrm{M}\right)$ was added as well, the glutamate-induced response remained unchanged (Fig. 5C, compared to control in Fig. 5A), suggesting that chloride ions were not implicated in the development of the depolarizing response. This later result demonstrates that glutamate- and GABA-induced PADs involve distinct mechanisms (Cattaert et al., 1994; Eccles et al., 1963; Gallagher et al., 1978). 
In order to verify that glutamate and GABA did not activate the same receptor-channel, we used a double-barreled micro-pipette to eject both drugs in the same area. Responses to glutamate and GABA evoked at different locations on the recorded CBT were compared (Fig. 6A). Such a protocol allowed us to determine that GABA and glutamate receptors were localized at distinct sites of the terminal tree (Fig. 6B). When the double-barreled micro-pipette was located near the first branching point of the CBTs (position 1 in Fig. 6A), only GABA succeeded in producing a depolarization, and a decrease in input resistance in the recorded CBT, while glutamate ejection did not elicit any response (Fig. 6B1). In contrast, when the double-barreled ejection pipette was located closer to the endings of CBTs (position 2 in Fig. 6A), a depolarizing response to glutamate and an input resistance decrease occurred in the recorded CBT (Fig. 6B2). Even at these locations, GABA remained able to produce the classical GABA-induced response in the recorded CBT.

Glutamate involves a non-NMDA type of receptor-channels.

Superfusion of various NMDA-receptor antagonists always failed to prevent the development of the depolarizing response to glutamate micro-application. As shown in Figure 7A, adding 2-amino-5-phosphonopentanoic acid (AP5, $\left.10^{-2} \mathrm{M}\right)$ or a mixture of 2-amino-3-phosphonopropionic acid $\left(\mathrm{AP} 3,10^{-2} \mathrm{M}\right)$ and 2-amino-7-phosphonoheptanoic acid (AP7, $\left.10^{-2} \mathrm{M}\right)$ to the perfusion saline did not affect the glutamate-induced depolarizing response in the recorded CBT. Ketamine, another NMDA receptor antagonist, did not prevent the glutamatergic response as well (data not shown). The conclusion that NMDA receptors are not involved in the presynaptic inhibition of $\mathrm{MN}$ origin is reinforced by the finding that, even in $\mathrm{Mg}^{2+}$-free saline, glycine had never any effects (data not shown).

By contrast, non-NMDA receptor antagonists diminished significantly (by a mean of $30 \%$ of decrease) the amplitude of the depolarization induced by glutamate micro-ejection. In 
the example presented in Figure $7 \mathrm{~B} 1$, addition of $\mathrm{CNQX}\left(10^{-3} \mathrm{M}\right)$ in the perfusion bath induced a reversible $23 \pm 3 \%$-decrease in amplitude of the glutamatergic response. Comparable results were obtained by superfusion of DNQX $\left(10^{-3} \mathrm{M}\right)$, another non-NMDA antagonist of glutamate (data not shown). In addition, kainate, a glutamate non-NMDA agonist, substituted for glutamate in the ejection micro-pipette was capable of producing depolarizing responses with the same characteristics as glutamate : their dose-dependence was comparable to glutamate-induced ones (Fig. 7B2, compare with histogram in Fig. 3B); as was the case for glutamate-evoked response, the kainate response reversed around $-55 \mathrm{mV}$ (data not shown); the kainate-evoked depolarization was accompanied by input resistance decrease comparable to the glutamate-induced one (data not shown). These results clearly demonstrate that glutamate responses recorded from CBTs were due to the activation of a non-NMDA type of receptor.

We investigated which ions permeate through the channel associated with this nonNMDA-type receptor, using various salines : a calcium-free saline, a chloride-free saline, and a half-sodium or half-potassium concentration salines (Fig. 8). The calcium-free as well as the chloride-free saline did not alter neither the spike shunt in the recorded CBTs, nor the amplitude of the glutamate-induced depolarization (not significant difference between the three thin lines corresponding to the linear regressions calculated from the values obtained under normal saline, calcium- or chloride-free salines; reversal potential $=-53 \pm 3 \mathrm{mV}$; Fig. 8 ). In contrary, when the sodium concentration (thick broken line; reversal potential $=-54 \pm 2 \mathrm{mV}$; Fig. 8) or the potassium concentration was lowered by $50 \%$ (thick line; reversal potential $=-58 \pm 2 \mathrm{mV}$; Fig. 8), the shunting effect on spike amplitude was reduced. Moreover, the slopes of both linear regressions, representing the relationships between the amplitude of the response and the imposed membrane potential, were significantly different from control ( $\mathrm{p}<0.001$ and $\mathrm{p}<0.01$ for sodium-free and potassium-free salines, respectively). Taken 
together, all these results strongly suggest that glutamate activated a kainate-like receptor-channel which was permeable to both $\mathrm{Na}^{+}$and $\mathrm{K}^{+}$ions.

\section{DISCUSSION}

The sdPADs are glutamatergic and originate from MNs.

During rhythmic motor activities, sdPADs recorded from CBTs present characteristics identical with glutamate-induced depolarizing responses : small amplitudes $(<5 \mathrm{mV})$, insensitivity to picrotoxin $\left(10^{-4} \mathrm{M}\right)$ and sensitivity to non-NMDA glutamate antagonists (CNQX and DNQX, $\left.10^{-3} \mathrm{M}\right)$. In addition several facts are strongly in favor of a excitatory MN origin for sdPADs : (1) sdPADs are strictly related to motor bursting activity of one or several MN groups (Fig. 1), (2) glutamate is the excitatory MN neurotransmitter, (3) motor nerve electrical stimulation produces a small amplitude depolarizing response $(<5 \mathrm{mV})$ with the same reversal potential as glutamate-evoked responses (data not shown), and (4) this response to motor nerve stimulation is sensitive to the same non-NMDA glutamate antagonists as sdPADs and glutamate-evoked responses, and insensitive to picrotoxin (data not shown). These characteristics common to sdPADs and glutamate-evoked depolarizing responses are not shared by GABAergic PADs (Cattaert et al., 1992). Although a common inhibitory MN has been described in crayfish (Bévengut et al., 1996), the neurotransmitter of which is GABA, we can exclude the participation of this common inhibitor in the responses observed in CBTs in response to motor nerve electrical stimulation, because sdPADs persist in the presence of picrotoxin.

The SAPADs and GABAergic PADs do not occur at the same location.

Immuno-histochemical studies have shown that locust mechano-sensory afferents possess GABA and glutamate input synapses (Watson et al., 1991). These authors 
demonstrated that both types of synapses were intermingled on most of the primary afferent axonal branches. In crayfish sensory afferents, although such immuno-histochemical studies have not yet been performed, we have demonstrated here that both input synapses exist too. However, it seems that glutamate and GABAergic responses occurred at distinct areas of the axonal arborization. Using a double-barreled ejection pipette, glutamate and GABA were applied at the same area (Marchand and Pearlstein, 1995). When the pipette was disposed close to the entry of the sensory axons within the ganglion, only GABA responses were evoked (Fig. 6B1). A similar location for PADs has been found by Cattaert and El Manira (1998a). When the pipette was placed in a more central area, GABA responses were still evoked, and glutamate responses became observable. The more central responses to GABA pressure-ejection may result from the GABA diffusing to the main GABA-receptor site demonstrated to exist in the area of CBT first branching point by immuno-histochemistry (Cattaert and El Manira, 1998a). However, similar diffusion would have also exist for the ejected glutamate, and therefore, glutamate receptor site would have been located even more centrally than the pipette.

The sdPADs involve a kainate-like glutamate receptor.

In this work, we described sensory terminals that present depolarizing inhibitory responses to glutamate micro-application. Although glutamate is generally considered as an excitatory neurotransmitter, it is now well-established that glutamate can also mediate inhibitory interactions in invertebrate nervous system (Miwa and Kawai, 1986; Kehoe, 1994; Marder and Paupardin-Tritsch, 1978; Miwa et al., 1993). Nevertheless, in most invertebrate models, glutamatergic inhibition is due to the activation of chloride channels as those involved in GABAergic inhibition and, therefore, shares the same pharmacological properties (Dubas, 1991; Franke et al., 1986b; Marder and Paupardin-Tritsch, 1978). In our preparation, 
we showed that the glutamate-mediated inhibition was not affected by the superfusion of picrotoxin (Figs. 2A and 5C), and modifying the extracellular concentration of chloride ions did not alter the glutamate-induced response in CBTs (Fig. 8). These results clearly indicate that glutamate did not act through the activation of a chloride channel, as it has been often described in invertebrate nervous system (Franke et al., 1986b; Lingle and Marder, 1981).

In crayfish muscles, Zufall et al. (1988) have shown that glutamate and acetylcholine activated the same receptor-channel. Because CBTs are cholinergic, one could suppose that the glutamatergic response we recorded from CBTs could be due to the activation of such a receptor. This assumption could be rejected because the muscle response was also abolished by picrotoxin. Moreover, each cholinergic antagonist tested always failed to prevent the glutamate-induced depolarization in CBTs (data not shown). In opposition, non-NMDA glutamate antagonists invariably reduced the amplitude of this depolarization (Fig. 7B). Moreover, kainate mimicked perfectly the action of glutamate when ejected onto CBTs (Fig. 7B) suggesting that the receptor involved in presynaptic inhibition resemble the excitatory kainate-type of glutamate receptor.

One could argue that, in our study, using high concentrations of antagonists resulted in weak effects (e.g., only $30 \%$ of blocking with CNQX, $10^{-3} \mathrm{M}$ ). However, we must keep in mind that pharmacological tools are rarely as efficient in invertebrates as they are in vertebrates. A number of invertebrate pharmacological studies used blocking agents at concentrations 10 to 1000 folds higher than the ones used in vertebrate to get a significant but rarely complete effect (Marder and Paupardin-Tritsch, 1978; Parker, 1994). For example, at the crayfish neuromuscular junction, $10^{-2} \mathrm{M}$ glutamate- $\gamma$-methylester only resulted in a $60 \%$ block of the glutamatergic excitatory junctional potentials (Lowagie and Gerschenfeld, 1974). Similarly, in the locust central nervous system, Sombati and Hoyle (1984) showed that the FETi (fast extensor tibialis motor nerve)-evoked depolarization could only be partially 
blocked by prolonged bath application of $5.10^{-3} \mathrm{M}$ of glutamate diethyl ester. In view of these established results, we can consider that the effects we show in this work are significant and support the demonstration that the glutamate receptors involved in the presynaptic inhibition originating from $\mathrm{MN}$ activity share some characteristics of the vertebrate kainate-type glutamate receptors. In opposition AP7 has been shown to efficiently block the crayfish NMDA receptor (Pfeiffer-Linn and Glantz, 1991), while it was totally ineffective in our system even when used at higher concentration (Fig. 7A). We therefore conclude that the glutamate receptor that mediates the presynaptic inhibition in sensory terminals are nonNMDA receptors, and probably of kainate type.

Presynaptic inhibition associated with sdPADs involves a new shunt mechanism.

Different kinds of mechanisms have been proposed for presynaptic inhibition. Several recent studies demonstrated the existence of a metabotropic control of neurotransmitter release, through various intracellular cascades of events (Scanziani et al., 1995; Christenson and Grillner, 1991; Schrader and Tasker, 1997; Sladeczek et al., 1993). Nevertheless, the most commonly described mechanism of presynaptic inhibition in primary afferent remains the shunt of the afferent action potential, induced by the massive opening of ion channels (Cattaert and El Manira, 1998b). As we described (Figs. 4B and 6B2), glutamate micro-application induced a strong decrease of the input resistance of CBTs, which resulted in the shunt of the afferent spikes (Fig. 4A). In the case of the GABA-mediated presynaptic inhibition, the action potential is shunted by a strong increase in chloride conductance (Cattaert et al., 1992; Cattaert et al., 1994; Cattaert and El Manira, 1998a,b; Gallagher et al., 1978; Segev, 1990). In opposite, we demonstrated that glutamate did not involve chloride ions. It seemed that glutamate shunt was due to the increase of a combined sodium-potassium conductance (Fig. 8). Cationic channels coupled to glutamate receptor have previously been 
reported to mediate inhibitory controls in crustacean neuromuscular junction and in mollusk interneurons (Miwa and Kawai, 1986; Kehoe, 1994; Marder and Paupardin-Tritsch, 1978). However, only $\mathrm{K}^{+}$ions were found to permeate through those receptor-channels, inducing subsequently hyperpolarizing responses. In crayfish sensory terminals, it appears that another type of glutamate receptor is responsible for the presynaptic inhibition of sensory spikes. The fact that kainate reproduced roughly the same response as glutamate suggests that the shunt of afferent action potential resulted from the opening of the non-specific $\mathrm{Na}^{+} / \mathrm{K}^{+}$channel associated to the kainate-type of glutamate receptor (Ogura et al., 1992; Mat et al., 1984; Sonhof and Buhrle, 1981; Lambert et al., 1981). This result is surprising because the kainate receptor has classically been described as involved in excitatory synapses. The glutamateinduced inhibition may be the result from a modification of the relative permeabilities of $\mathrm{Na}^{+}$ and $\mathrm{K}^{+}$ions, which would be specific of the presynaptic receptor-channel in crayfish CBTs (compared to the excitatory $\mathrm{Na}^{+} / \mathrm{K}^{+}$channel encountered in crayfish muscle; Dudel, 1974; Franke et al., 1986a). Such an effect could be due to the channel having a larger permeability for $\mathrm{K}^{+}$ions than the one encountered in excitatory kainate receptor-channel, while $\mathrm{Na}^{+}$ permeability would be strongly reduced. Such relative permeabilities to $\mathrm{Na}^{+}$and $\mathrm{K}^{+}$would explain the very small amplitude of the depolarization induced by glutamate in CBTs. Functionally, such characteristics would exclude any excitatory effect on the presynaptic neurotransmitter release but would allow the shunt of the afferent action potentials. Considering the efficiency of the shunt performed on spike amplitude by such a small depolarization (a $2 \mathrm{mV}$-depolarization elicited a mean decrease of spike amplitude of around $20 \%$; Fig. 4A), we can suppose that the amplitude of the depolarization did not completely reflect the increase in conductance. This is confirmed by the observation of large variations of input resistance of CBTs during glutamate micro-ejection (Fig. 4B). 
Functional significance of the direct inhibitory control of CBTs by the MNs.

A number of authors investigated the role of presynaptic inhibition in the central nervous system. GABAergic presynaptic inhibition has been described to play a role in interjoint coordination during locomotion in crayfish (El Manira et al., 1991), and in the lamprey (Grillner et al., 1991). In both vertebrates and invertebrates, presynaptic inhibition originating from central networks has been proposed to be involved in the selection of the sensory information adapted to the voluntary movement that is executed (Asanuma, 1989; Rudomin et al., 1993). In crayfish, but similar results were obtain in the cat (Gossard et al., 1991), Cattaert et al. (1992) described bursts of PADs that occurred exclusively at the transition between the activities of depressor MNs and levator MNs during organized fictive locomotion (see also Fig. 1). Le Ray and Cattaert (1997) identified a polysynaptic pathway involved in the expression of the assistance reflex in crayfish locomotor network. They proposed that the rhythmic PADs previously described by Cattaert et al. (1992) were one of the control mechanisms that regulate the shift between resistance and assistance reflexes. In the locust, GABA-mediated presynaptic inhibition originates from the sensory afferents of the femoral chordotonal organ (Burrows and Laurent, 1993). By this mean, afferents accomplish a local gain control of the sensory input (Burrows and Matheson, 1994). Here, we described a new type of presynaptic inhibition of the sensory afferents exerted directly by the MNs.

Although the exact function of such retrograde inhibitory control remains to be determined, there exist several observations that may help to understand its role in the locomotor network. First, "physiological" responses to glutamate application could only be met in the CBTs by applying an electrical stimulation to the whole motor nerve (Fig. $2 \mathrm{~B}$ and Table 1), while it was never possible to observe any depolarizations in the CBTs when a single MN was intracellularly stimulating. These observations indicate the existence of an activation threshold of this negative presynaptic control (Fig. 9). Second, when every 
reciprocal inhibitions were blocked by picrotoxin superfusion, all MNs fired synchronously which induced large depolarizations in CBTs (Fig. 2A). These two observations suggest that MN-induced presynaptic inhibition could exert an automatic gain control of the sensory input in order not to saturate the MN activity. Contrary to the gain-control system described by Burrow and Matheson (1994) that used the sensory activity as origin of the negative control, the mechanism we describe uses the MN activity. This hypothesis is consistent with the fact that PADs of sensory origin does not seem to exist in CBTs. Consequently, the regulation of the gain of the sensory input synapses is devoted to the other element of sensory-motor loop, the MN itself (Fig. 9).

\section{ACKNOWLEDGEMENTS}

We are grateful to Dr. F. Clarac for laboratory facilities. This work was supported by the Centre National de la Recherche Scientifique (CNRS). D. Le Ray received a fellowship from the Ministère de l'Enseignement Supérieur Français. 


\section{ABBREVATIONS}

CBCO coxo-basipodite chordotonal organ

CBT(s) CBCO sensory terminal(s)

CNQX 6-cyano-7-dinitroquinoxaline-2,3-dione

DNQX 6,7-dinitroquinoxaline-2,3-dione

GABA $\gamma$-amino-butyric acid

$\mathrm{MN}(\mathrm{s})$ motor neuron(s)

NMDA $N$-methyl- $D$-aspartate

PAD(s) primary afferent depolarization(s)

sdPAD(s) slowly developing PAD(s) 


\section{REFERENCES}

Asanuma, H. (1989) Function of somesthesic input during voluntary movements. In: The motor cortex. Raven Press, New York, pp. 69-75.

Berry, M. S. and Pentreath, V. W. (1976) Criteria for distinguishing between monosynaptic and polysynaptic transmission. Brain Res., 105, 1-20.

Bévengut, M., Cattaert, D. and Clarac, F. (1996) Synaptic connections of the common inhibitory motoneurone within the fifth thoracic ganglion of crayfish. J. Comp. Physiol. A, 178, 337-350.

Burrows, M. and Laurent, G. (1993) Synaptic potentials in the central terminals of locust proprioceptive afferents generated by other afferents from the same sense organ. $J$. Neuroscience, 13(2), 808-819.

Burrows, M. and Matheson, T. (1994) A presynaptic gain control mechanism among sensory neurons of a locust leg proprioceptor. J. Neurosci., 14, 272-282.

Cattaert, D., Araque, A., Buño, W. and Clarac, F. (1994) Motor neurones of the crayfish walking system possess $\mathrm{TEA}^{+}$-revealed regenerative electrical properties. J. exp. Biol., 188, 339-345.

Cattaert, D. and El Manira, A. (1998) Presynaptic inhibitory mechanisms in primary afferents of the crayfish. I-Electrophysiological and anatomical analysis. Eur. J. Neurosci. (submitted for publication).

Cattaert, D. and El Manira, A. (1998) Presynaptic inhibitory mechanisms in primary afferents of the crayfish. II-Simulations. Eur. J. Neurosci. (submitted for publication). 
Cattaert, D., El Manira, A. and Clarac, F. (1992) Direct evidence for presynaptic inhibitory mechanisms in crayfish sensory afferents. J. Neurophysiol., 67, 610-624.

Cattaert, D., El Manira, A. and Clarac, F. (1994) Chloride conductance produces both presynaptic inhibition and antidromic spikes in primary afferents. Brain Res., 666 , 109-112.

Chrachri, A. and Clarac, F. (1990) Fictive locomotion in the fourth thoracic ganglion of the crayfish, Procambarus clarkii. J. Neuroscience, 10, 707-719.

Christenson, J., Bongianni, F., Grillner, S. and Hokfelt, T. (1991) Putative GABAergic input to axons of spinal interneurons and primary sensory neurons in the lamprey spinal cord as shown by intracellular Lucifer yellow and GABA immunohistochemistry. Brain Res., 538, 313-318.

Christenson, J. and Grillner, S. (1991) Primary afferents evoke excitatory amino acid receptormediated EPSPs that are modulated by presynaptic GABAB receptors in lamprey. $J$. Neurophysiol., 66, 2141-2149.

Clarac, F. and Cattaert, D. (1996) Invertebrate presynaptic inhibition and motor control. Exp. Brain Res., 112(2), 163-180.

Davidoff, R. A. (1972) GABA antagonism and presynaptic inhibition in the frog spinal cord. Science, $175,331-333$.

Dubas, F. (1991) Actions of putative amino acid neurotransmitters on the neuropile arborizations of locust flight motoneurones. J. exp. Biol., 155, 337-356. 
Dudel, J., (1974) Nonlinear voltage dependence of excitatory synaptic current in crayfish muscle. Pflugers Arch., 352, 227-241.

Dudel, J. and Kuffler, S. W. (1961) Presynaptic inhibition at the crayfish neuromuscular junction. J. Physiol. (Lond), 155, 543-562.

Eccles, J. C., Schmidt, R. F. and Willis, W. D. (1962) Presynaptic inhibition of the spinal monosynaptic reflex pathway. J. Physiol. (Lond), 161, 282-297.

Eccles, J. C., Schmidt, R. F. and Willis, W. D. (1963) Pharmacological studies on presynaptic inhibition. J. Physiol. (Lond), 168, 500-530.

El Manira, A. and Clarac, F. (1991) GABA-mediated presynaptic inhibition in crayfish primary afferents by non-A, non-B GABA receptors. Eur. J. Neurosci., 3, 1208-1218.

El Manira, A. and Clarac, F. (1994) Presynaptic inhibition is mediated by histamine and GABA in the crustacean escape reaction. J. Neurophysiol., 71, 1088-1095.

El Manira, A., DiCaprio, R. A., Cattaert, D. and Clarac, F. (1991) Monosynaptic interjoint reflexes and their central modulation during fictive locomotion in crayfish. Eur. J. Neurosci., 3, 1219-1231.

Frank, K. and Fuortes, M. G. F. (1957) Presynaptic and postsynaptic inhibition of monosynaptic reflexes. Fed. Proc. Fed. Am. Soc. Exp. Biol., 16, 39-40.

Franke, C., Hatt, H. and Dudel, J. (1986a) The excitatory glutamate-activated channel recorded in cell-attached and excised patches from the membranes of tail, leg and stomach muscles of crayfish. J. Comp. Physiol. [A]., 159, 579-589. 
Franke, Ch., Hatt, H. and Dudel, J. (1986b) The inhibitory chloride channel activated by glutamate as well as gamma-amino-butyric acid (GABA). J. Comp. Physiol. [A]., 159, 591-609.

Gallagher, J. P., Higashi, H. and Nishi, S. (1978) Characterization and ionic basis of GABAinduced depolarizations recorded in vitro from cat primary afferent neurones. $J$. Physiol. (Lond), 275, 263-282.

Gossard, J.-P., Cabelguen, J.-M. and Rossignol, S. (1989) Intra-axonal recordings of cutaneous primary afferents during fictive locomotion in the cat. J. Neurophysiol., 62, 1177-1188.

Gossard, J.-P., Cabelguen, J.-M. and Rossignol, S. (1991) An intracellular study of muscle primary afferents during fictive locomotion in the cat. J. Neurophysiol., 65, 914-926.

Grillner, S., Wallen, P., Brodin, L. and Lansner, A. (1991) Neuronal network generating locomotor behavior in lamprey: circuitry, transmitters, membrane properties, and simulation. Annu. Rev. Neurosci., 14, 169-199.

Hori, Y., Endo, K. and Takahashi, T. (1992) Presynaptic inhibitory action of enkephalin on excitatory transmission in superficial dorsal horn of rat spinal cord. J. Physiol. (Lond. ), 450, 673-685.

Kehoe, J. S. (1994) Glutamate activates a $\mathrm{K}^{+}$conductance increase in Aplysia neurons that appears to be independent of G proteins. Neuron, 13, 691-702.

Kennedy, D., Calabrese, R. L. and Wine, J. J. (1974) Presynaptic inhibition: primary afferent depolarization in crayfish neurons. Science, 186, 451-454. 
Kirk, M. D. (1985) Presynaptic inhibition in the crayfish CNS: pathways and synaptic mechanisms. J. Neurophysiol., 54, 1305-1325.

Kretz, R., Saphiro, E., Bailey, C. H., Chen, M. and Kandel, E. R. (1986) Presynaptic inhibition produced by an identified presynaptic inhibitory neuron. II. Presynaptic conductance changes caused by histamine. J. Neurophysiol., 55, 131-146.

Lambert, J. D. C., Flatman, J. A. and Engberg, I. (1981) Actions of excitatory amino acids on membrane conductance and potential in motoneurons. In: DiChiara, G. and Gessa, G. L. (eds), Glutamate as a neurotransmitter. Raven Press, New York, pp. 205-216.

Le Ray, D. and Cattaert, D. (1997) Neural mechanisms of reflex reversal in coxo-basipodite depressor motor neurons of the crayfish. J. Neurophysiol., 77(4), 1963-1978.

Lingle, C. and Marder, E. (1981) A glutamate-activated chloride conductance on a crustacean muscle. Brain Res., 212, 481-488.

Lowagie, C. and Gerschenfeld, H. M. (1974) Glutamate antahonists at crayfish neuromuscular junction. Nature 248, 533-535.

Marchand, A. R., Barnes, W. J. P. and Cattaert, D. (1997) Primary afferent depolarizations of sensory origin within contact-sensitive mechanoreceptive afferents of a crayfish leg. $J$ Neurophysiol. 77, 3340-3354.

Marchand, A. R. and Pearlstein, E. (1995) A simple dual pressure-ejection system and calibration method for brief local application of drugs and modified salines. $J$. Neurosci. Methods, 60, 99-105. 
Marder, E. and Paupardin-Tritsch, D. (1978) The pharmacological properties of some crustacean neuronal acetylcholine, gamma-aminobutyric acid, and L-glutamate responses. J. Physiol. (Lond), 280, 213-236.

Mat, J. A., Kerkut, G. A. and Walker, R. J. (1984) The ionic mechanisms associated with the excitatory response of kainate, L-glutamate, quisqualate, ibotenate, AMPA and methyltetrahydrofolate on leech Retzius cells. Comp. Biochem. Physiol. C., 77, 115126.

Miwa, A. and Kawai, N. (1986) Presynaptic glutamate receptor--possible involvement of a K+ channel. Brain Res., 385, 161-164.

Miwa, A., Robinson, H. and Kawai, N. (1993) Presynaptic glutamate receptors depress inhibitory postsynaptic transmission in lobster neuromuscular synapse. $J$. Neurophysiol., 1159-1167.

Ogura, A., Nakazawa, M. and Kudo, Y. (1992) Further evidence for calcium permeability of non-NMDA receptor channels in hippocampal neurons. Neurosci. Res., 12, 606-616.

Parker, D. (1994) Glutamatergic transmission between antagonistic motor neurones in the locust. J. Comp. Physiol. A 175, 737-748.

Pearlstein, E., Watson, A. H. D., Bévengut, M. and Cattaert, D. (1998) Inhibitory connections between antagonistic motoneurones of the crayfish walking legs. J. Comp. Neurol. (submitted for publication).

Pfeiffer-Linn, C. and Glantz, R. M. (1991) An arthropod NMDA receptor. Synapse 9, 35-42. 
Rudomin, P. (1990) Presynaptic inhibition of muscle spindle and tendon organ afferents in the mammalian spinal cord. Trends Neurosci., 13, 499-505.

Rudomin, P., Quevedo, J. and Eguibar, J. R. (1993) Presynaptic modulation of spinal reflexes. Curr. opin. Neurobiol., 3, 997-1004.

Rudomin, P., Romo, R. and Mendel, L. M. (1998) Presynaptic inhibition and neural control. Oxford University Press, New York.

Scanziani, M., Gahwiler, B. H. and Thompson, S. M. (1995) Presynaptic inhibition of excitatory synaptic transmission by muscarinic and metabotropic glutamate receptor activation in the hippocampus: are Ca2+ channels involved? Neuropharmacology, 34, 1549-1557.

Schrader, L. A. and Tasker, J. G. (1997) Presynaptic modulation by metabotropic glutamate receptors of excitatory and inhibitory synaptic inputs to hypothalamic magnocellular neurons. J. Neurophysiol., 77, 527-536.

Segev, I., (1990) Computer study of presynaptic inhibition controlling the spread of action potentials into axonal terminals. J. Neurophysiol., 63, 987-998.

Seybold, V. S. (1986) Neurotransmitter receptors sites in the spinal cord. In: Yaksh, T. L. (ed), Spinal afferent processing. Plenum Press, New York, pp. 165-191.

Singer, J. H., Bellingham, M. C. and Berger, A. J. (1996) Presynaptic inhibition of glutamatergic synaptic transmission to rat motoneurons by serotonin. J. Neurophysiol., 76, $799-807$. 
Sladeczek, F., Momiyama, A. and Takahashi, T. (1993) Presynaptic inhibitory action of a metabotropic glutamate receptor agonist on excitatory transmission in visual cortical neurons. Proc. R. Soc. Lond. B. Biol. Sci., 253, 297-303.

Sonhof, U. and Buhrle, Ch. (1981) An analysis of glutamate-induced ion fluxes across the membrane of spinal motoneurons of the frog. In: DiChiara, G. and Gessa, G. L. (eds), Glutamate as a neurotransmitter. Raven Press, New York, pp. 195-204.

Van Harreveld, A., (1980) L-proline as a glutamate antagonist at a crustacean neuromuscular junction. J. Neurobiol., 11, 519-529.

Watson, A. H. D., Storm-Mathisen, J. and Ottersen, O. P. (1991) GABA and glutamate-like immunoreactivity in processes presynaptic to afferents from hair plates on the proximal joints of the locust leg. J. Neurocytol., 20, 796-809.

Zufall, F., Franke, C. and Hatt, H. (1988) Acetylcholine activates a chloride channel as well as glutamate and GABA. Single channel recordings from crayfish stomach and opener muscles. J. Comp. Physiol. [A]., 163, 609-620. 


\section{TABLE LEGEND}

TABLE 1. Examples of CBT responses to motor nerve antidromic stimulation. The effectiveness of the depolarizing response is symbolized by a number of "+", ranging from "0" (no response) to "+++" (maximum response). (Pro, protractor nerve; Rem, remotor nerve; aLev and pLev, anterior and posterior levator nerves; Dep, depressor nerve). 


\section{FIGURE LEGENDS}

FIG. 1. Dual presynaptic control of sensory afferent signals. During pharmacologically induced fictive locomotion, alternated activities are recorded from the levator (Lev $n$ ) and the depressor (Dep n) antagonistic motor nerves. During such motor activity, two distinct depolarizing events could be recorded from the CBCO sensory terminals (CBT) : first, bursts of classically described PADs, related to the locomotor rhythm, occurred at the transition between Dep and Lev bursts; second, slowly developing PADs (sdPADs) were recorded in phase with the bursting activity of one of the motor nerve (here the levator). The occurrence and time course of sdPADs were very strictly related to the levator instantaneous frequency (Lev n Inst. Freq.).

FIG. 2. Pharmacology of sdPADs. (A) Perfusing picrotoxin (PTX, 10 $0^{-4} \mathrm{M}$ ) blocked the classical GABA-mediated PADs, and induced synchronous bursts in all motor nerves. During these synchronous bursts, sdPAD amplitudes were larger (about $4 \mathrm{mV}$ ); they were significantly reduced by superfusion of a mixture of CNQX and DNQX $\left(10^{-3} \mathrm{M}\right.$; see histogram). (B) Electrical antidromic stimulation of a motor nerve (here, stimulation of the anterior levator nerve: Lev $\mathrm{n} \mathrm{St}$ ) produced depolarizing responses in CBT (top trace). When DNQX $\left(10^{-3} \mathrm{M}\right)$ was added to the perfusion bath (middle trace), the mean response showed a decrease of $45 \%$ when compared to control (dashed line). A partial recovery was achieved after removing the DNQX from the bath (wash, bottom trace). Each trace represents the average of 30 raw data.

FIG. 3. Pressure-applied glutamate induced depolarizations in CBTs. (A) Simplified drawing of the experimental protocol. Glutamate (Glu) was pressure-ejected in the vicinity of the thin 
branches of CBTs. Responses were recorded intracellularly from one CBT. (B) Dose-dependence of the response to glutamate application. Histogram demonstrated an almost linear relationship. (C) The glutamate-induced response reversed for potentials above $-55 \mathrm{mV}$.

FIG. 4. Shunting properties of the CBT response to glutamate (Glu) application. (A) The amplitude of electrically-triggered sensory spikes was dramatically reduced (23\%) during the glutamate-induced response. The shunt of action potentials lasted throughout the depolarization (in inset, middle parts of the spikes are truncated). (B) Measurements of the input resistance during glutamate micro-application at the resting potential (top) and at a potential above the reversal potential of the response (bottom). In each case, the decrease of input resistance was upper than $60 \%$.

FIG. 5. Glutamate (Glu)-induced PADs were tetrodotoxin $\left(5.10^{-7} \mathrm{M}\right)$-resistant, indicating a direct action of glutamate onto CBTs, and picrotoxin $\left(2.10^{-4} \mathrm{M}\right)$-resistant, suggesting that chloride ions were not involved.

FIG. 6. Comparison between glutamate (Glu)- and GABA-induced PADs. (A) Simplified drawing of the experimental protocol. Both neurotransmitters were pressure-applied at the same location using a double-barreled pipette, within two distinct areas of the CBTs: (1) at their entry within the ganglion, and (2) $250 \mu \mathrm{m}$ forward. (B) At location (1), CBTs only displayed the classical response to GABA micro-ejection. In contrast, when they were recorded within their thinner branches and when neurotransmitters were applied forward within the ganglion, CBTs displayed responses to both GABA and glutamate micro-application (2). Insets present the input resistance decrease elicited by GABA (1), or by GABA and glutamate (2). 
FIG. 7. Glutamate-induced depolarizations were affected by the non-NMDA pharmacological tools. (A) Lack of effect of the NMDA antagonists (AP3, AP7 and AP5) on the depolarizations induced by glutamate (Glu) micro-ejection. (B) Bath-application of CNQX, a non-NMDA antagonist of glutamate receptors, strongly decreased (23\%) the amplitude of the glutamate-induced depolarization; this effect was reversible (1). Kainate (KA), substituted for glutamate within the ejection micro-pipette, reproduced the dose-dependent development of a depolarizing response in the CBTs (2; compare with Fig. 3B).

FIG. 8. Ionic bases of the glutamate-induced depolarizations. Responses to glutamate ejection were plotted against the holding potential in five different salines. Neither the calcium-free nor the chloride-free salines significantly changed the responses (linear regressions did not significantly differ from that of control saline; 3 thin lines); the corresponding reversal potential of the response was $-54 \mathrm{mV}$. The half-concentrated potassium saline induced an increase in the regression slope $(\mathrm{p}<0.01)$, and pulled the reversal potential to slightly more negative values $(-58 \mathrm{mV}$; thick line). In opposite, the half-concentrated sodium saline decreased the regression slope $(\mathrm{p}<0.001)$ but did not significantly modified the reversal potential of the response (thick broken line).

FIG. 9. Functional scheme of respective roles of GABA- and glutamate-mediated presynaptic inhibition. During rhythmic activation of MNs by the locomotor central pattern generator, the classical GABAergic presynaptic inhibition involves specialized interneurons (PADIs; Kirk, 1985) that phasically select the sensory inputs according to the motor program. In opposite, during high level of MN activity, the MNs themselves exert a presynaptic gain control onto sensory inputs (see discussion). 


\begin{tabular}{|c|c|c|c|c|c|}
\hline Terminals & Pro $\mathrm{n}$ & Rem $\mathrm{n}$ & aLev $\mathrm{n}$ & pLev $\mathrm{n}$ & Dep $\mathrm{n}$ \\
\hline CBT 1 & ++ & ++ & 0 & ++ & + \\
\hline CBT 2 & + & ++ & +++ & 0 & ++ \\
\hline CBT 3 & +++ & 0 & 0 & 0 & 0 \\
\hline CBT 4 & ++ & 0 & 0 & 0 & 0 \\
\hline CBT 5 & 0 & ++ & 0 & 0 & +++ \\
\hline CBT 6 & 0 & + & +++ & 0 & +++ \\
\hline CBT 7 & 0 & 0 & ++ & 0 & 0 \\
\hline CBT 8 & 0 & 0 & ++ & 0 & ++ \\
\hline CBT 9 & 0 & 0 & ++ & 0 & 0 \\
\hline CBT 10 & 0 & 0 & 0 & + & 0 \\
\hline CBT 11 & 0 & 0 & 0 & + & 0 \\
\hline CBT 12 & 0 & 0 & 0 & +++ & 0 \\
\hline CBT 13 & 0 & 0 & 0 & ++ & 0 \\
\hline CBT 14 & 0 & 0 & 0 & 0 & ++ \\
\hline CBT 15 & 0 & 0 & 0 & 0 & ++ \\
\hline CBT 16 & 0 & 0 & 0 & 0 & ++ \\
\hline CBT 17 & 0 & 0 & 0 & 0 & + \\
\hline
\end{tabular}




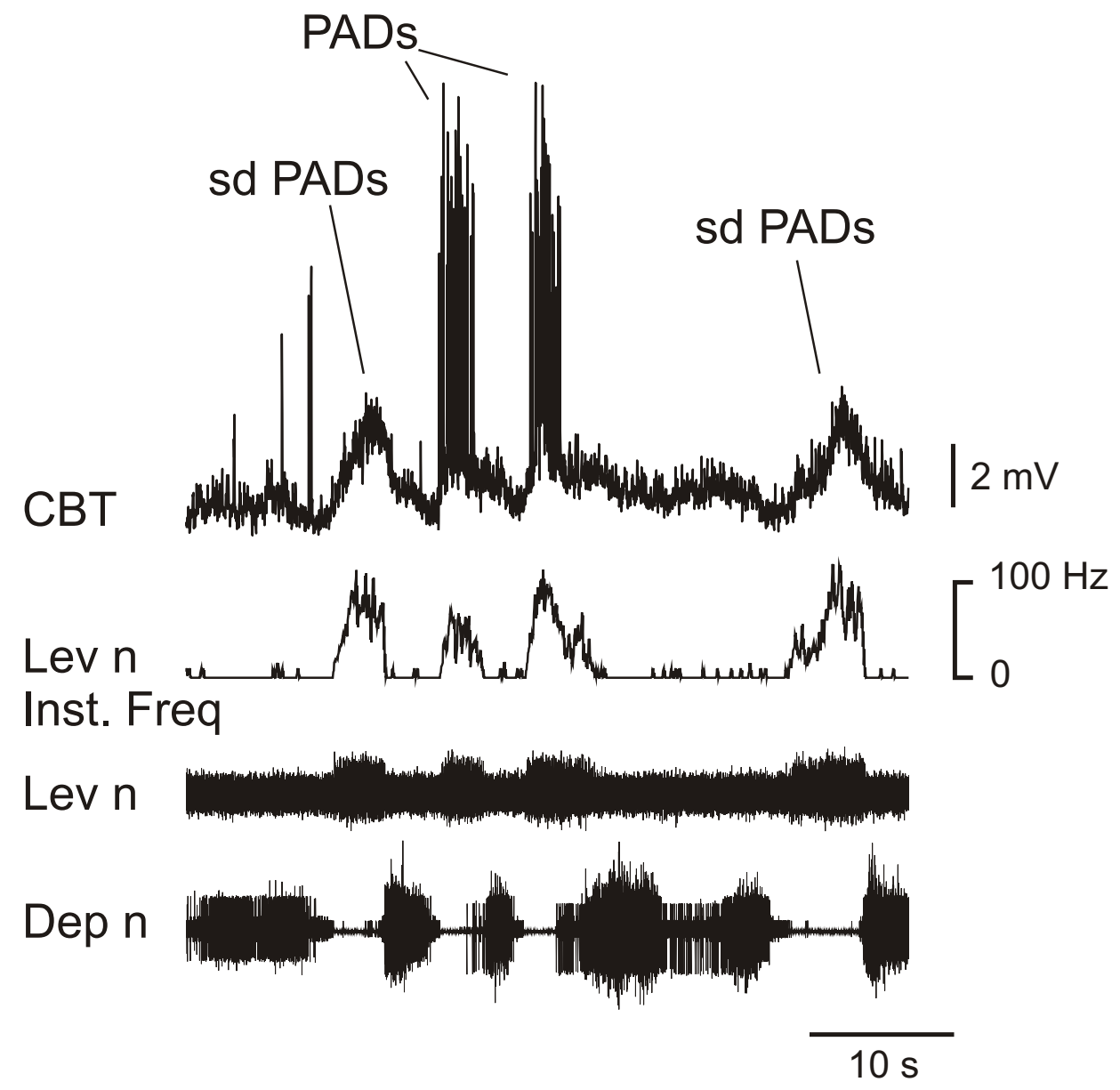


A Picrotoxin $10^{-4} \mathrm{M}$
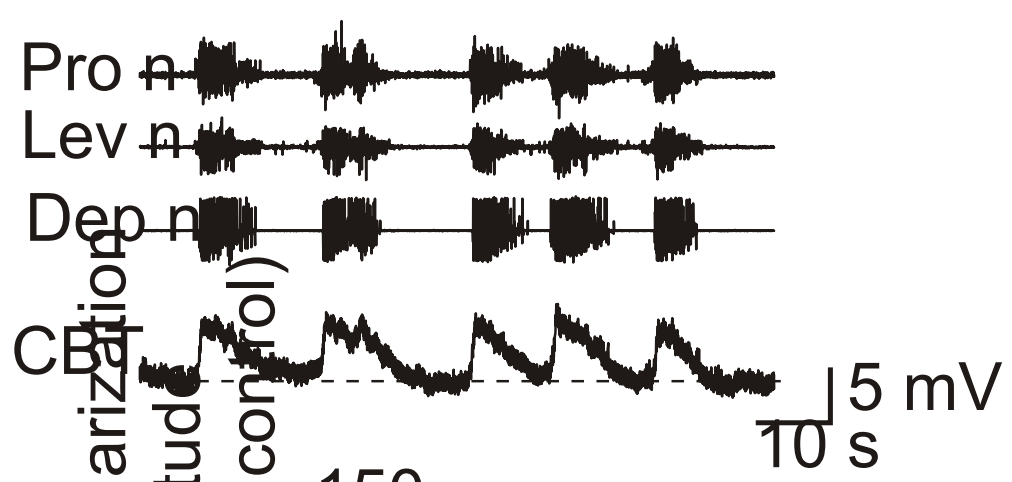

증 $150 \quad 10 \mathrm{~s}$

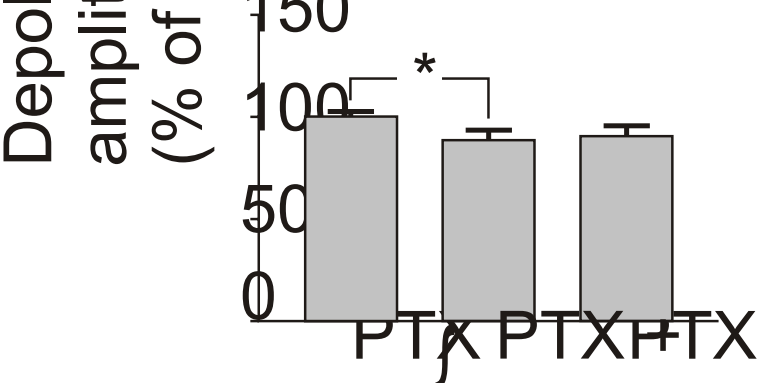

controinaxash

B

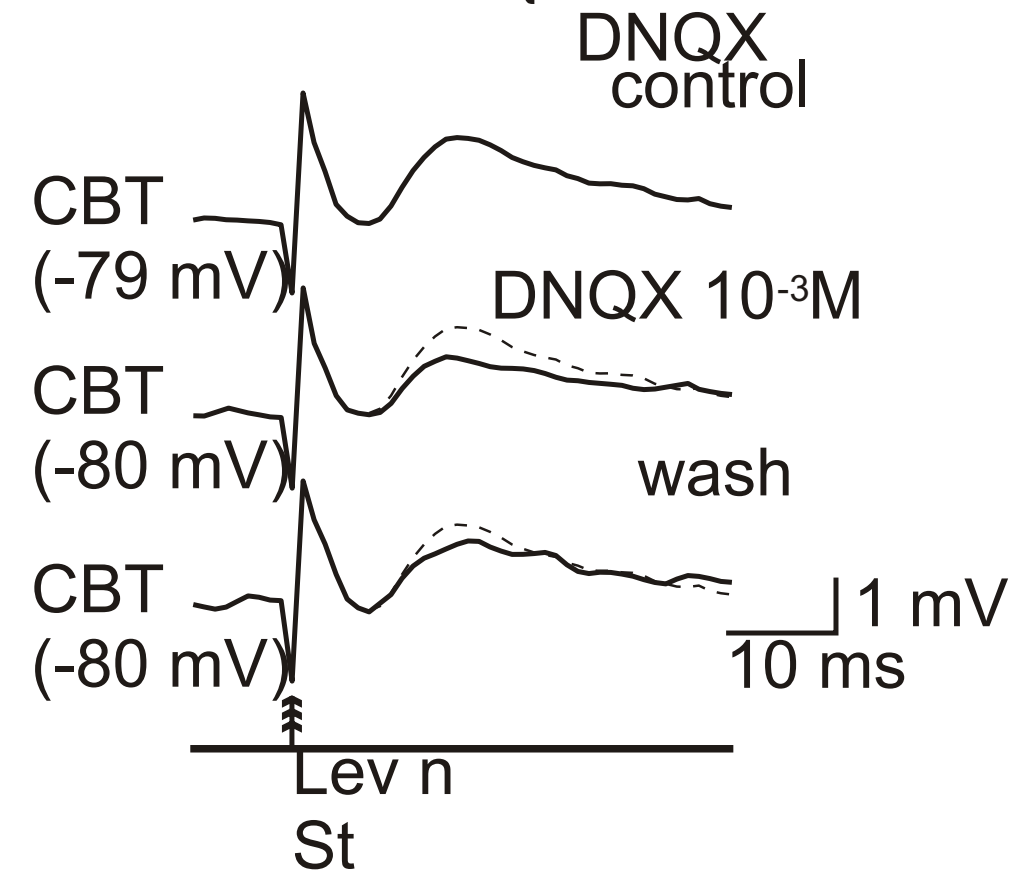


A

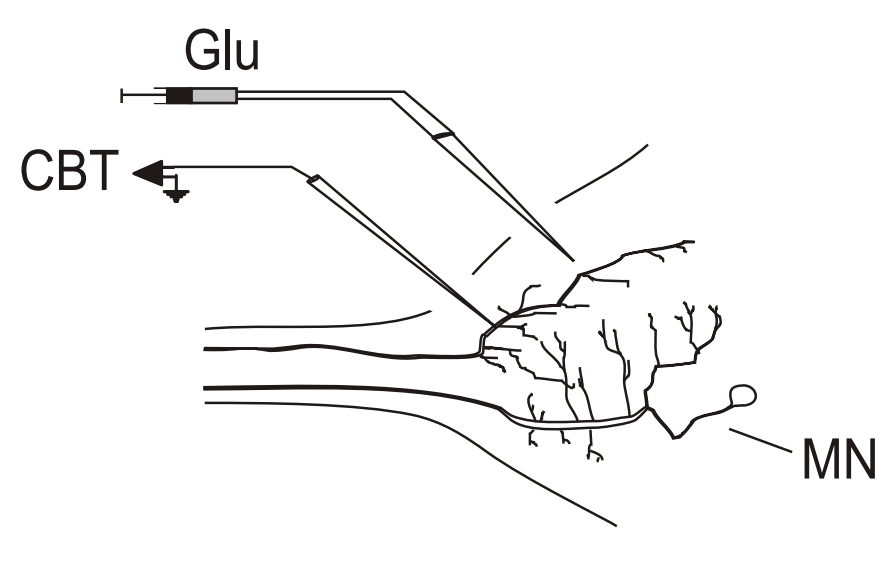

B
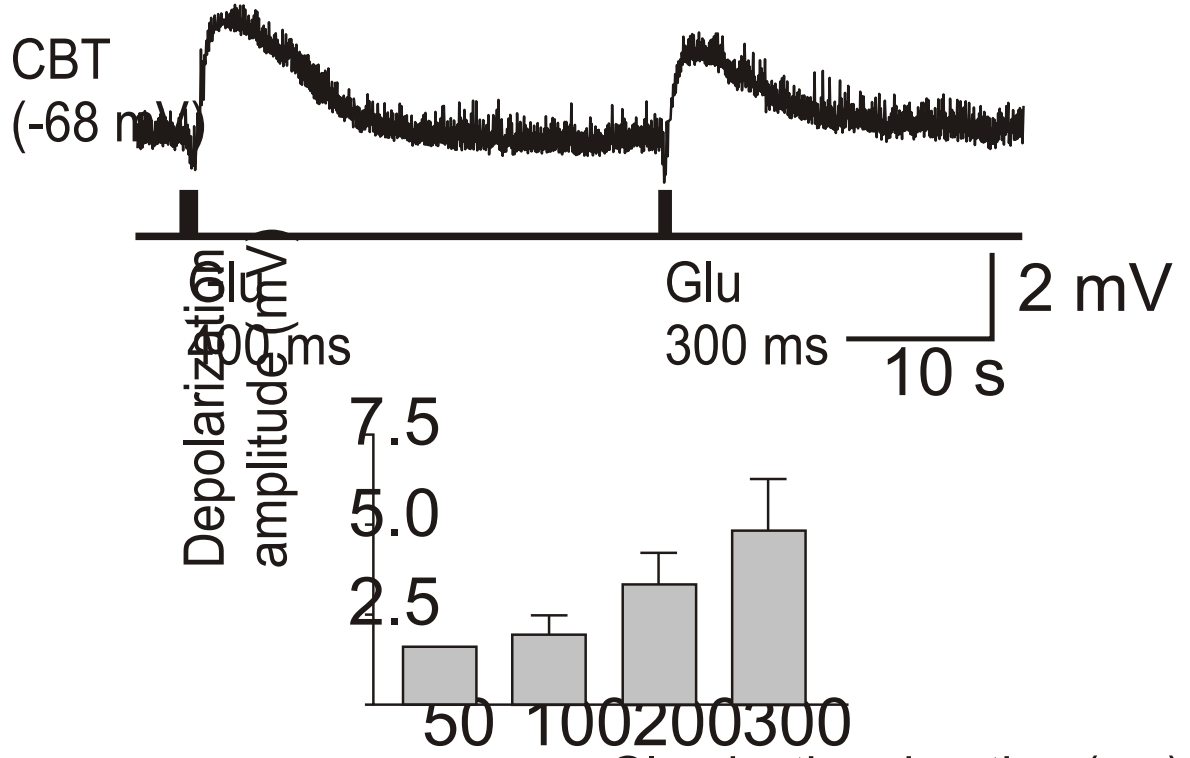

Glu ejection duration (ms)

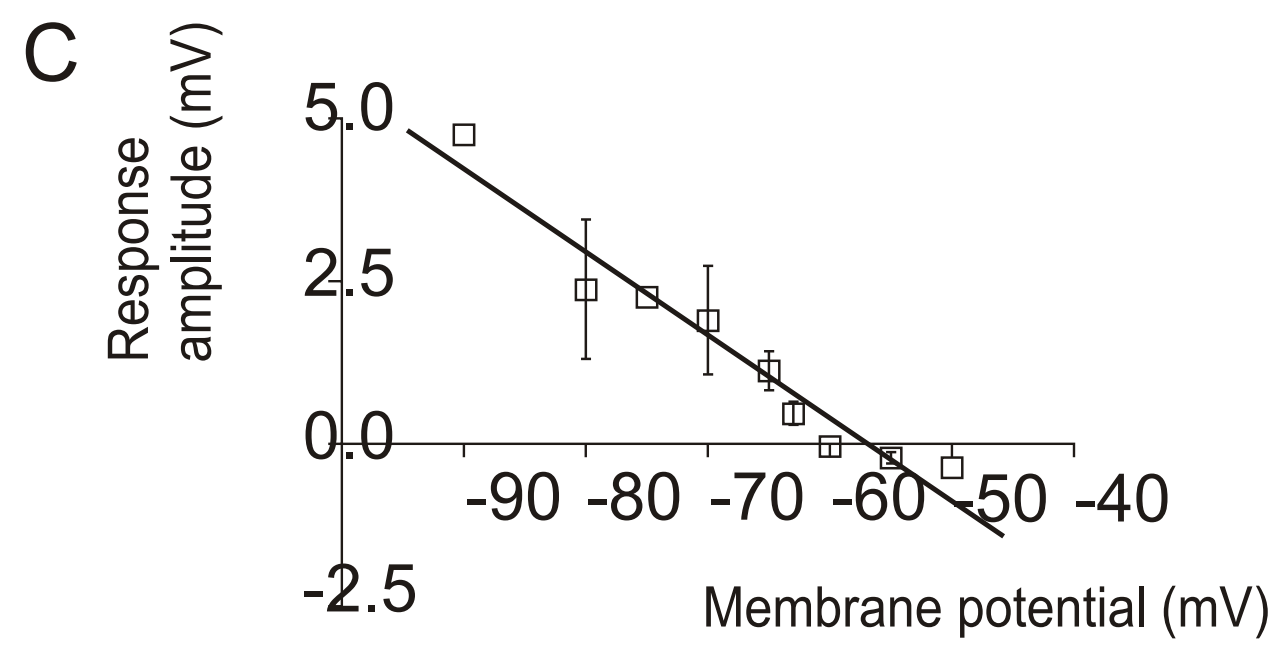


A

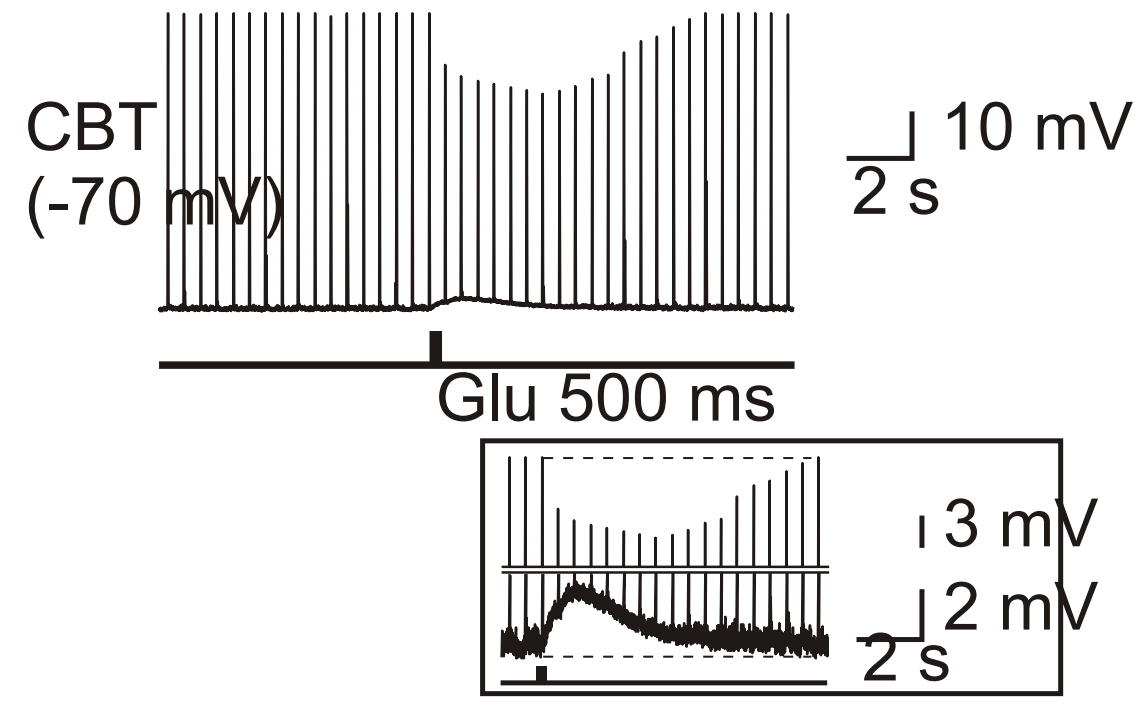

B

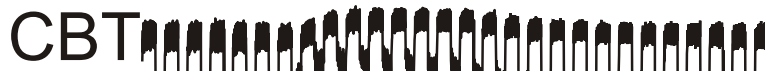
(-60 mWNA)

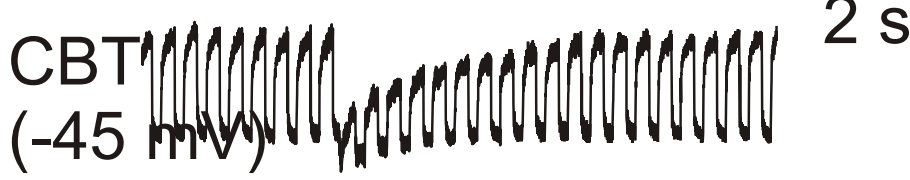

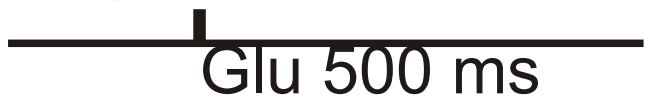


A Control

B Tetrodotoxin

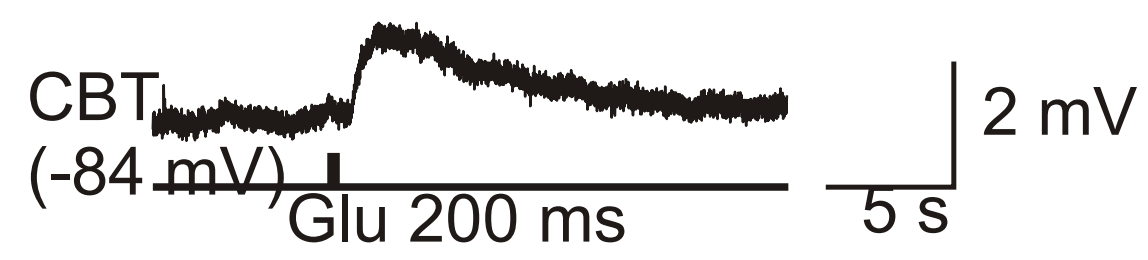

C Picrotoxin

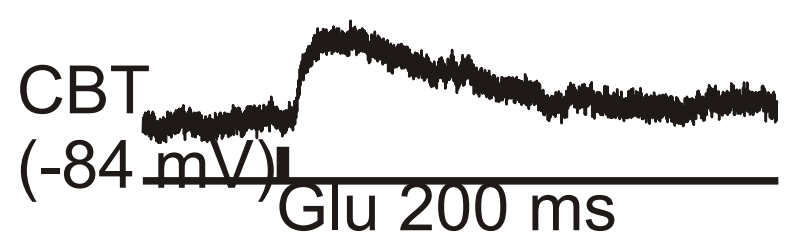




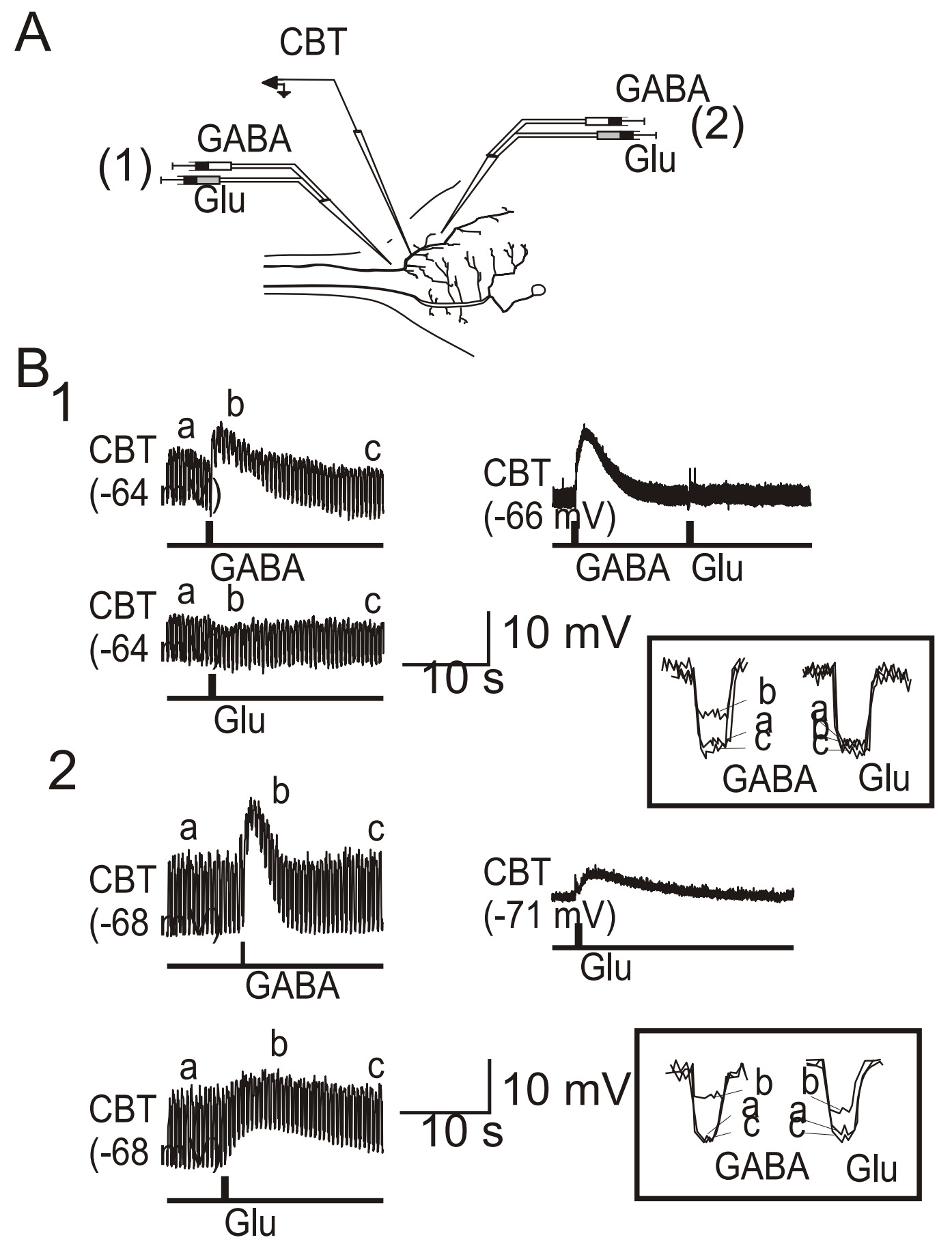




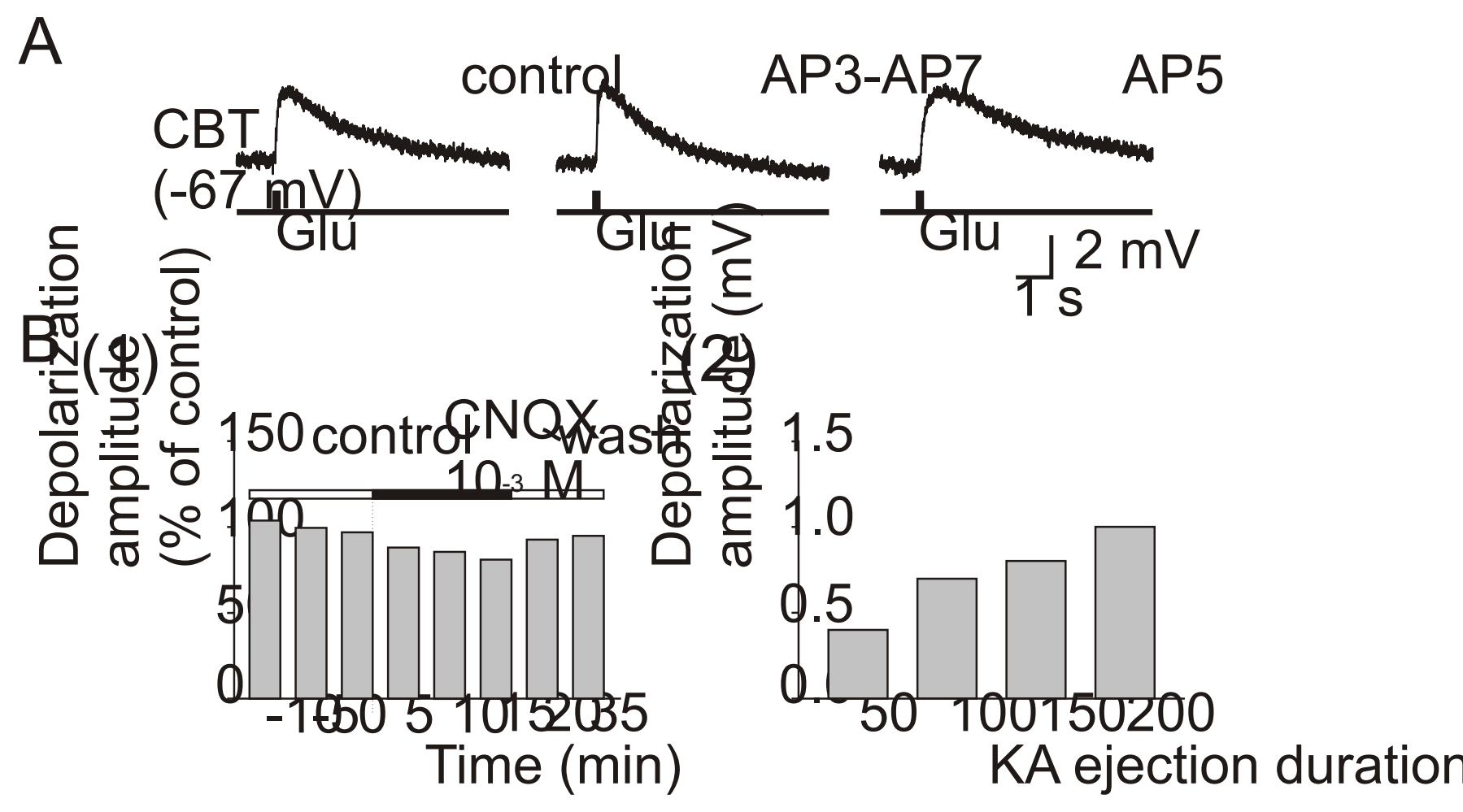




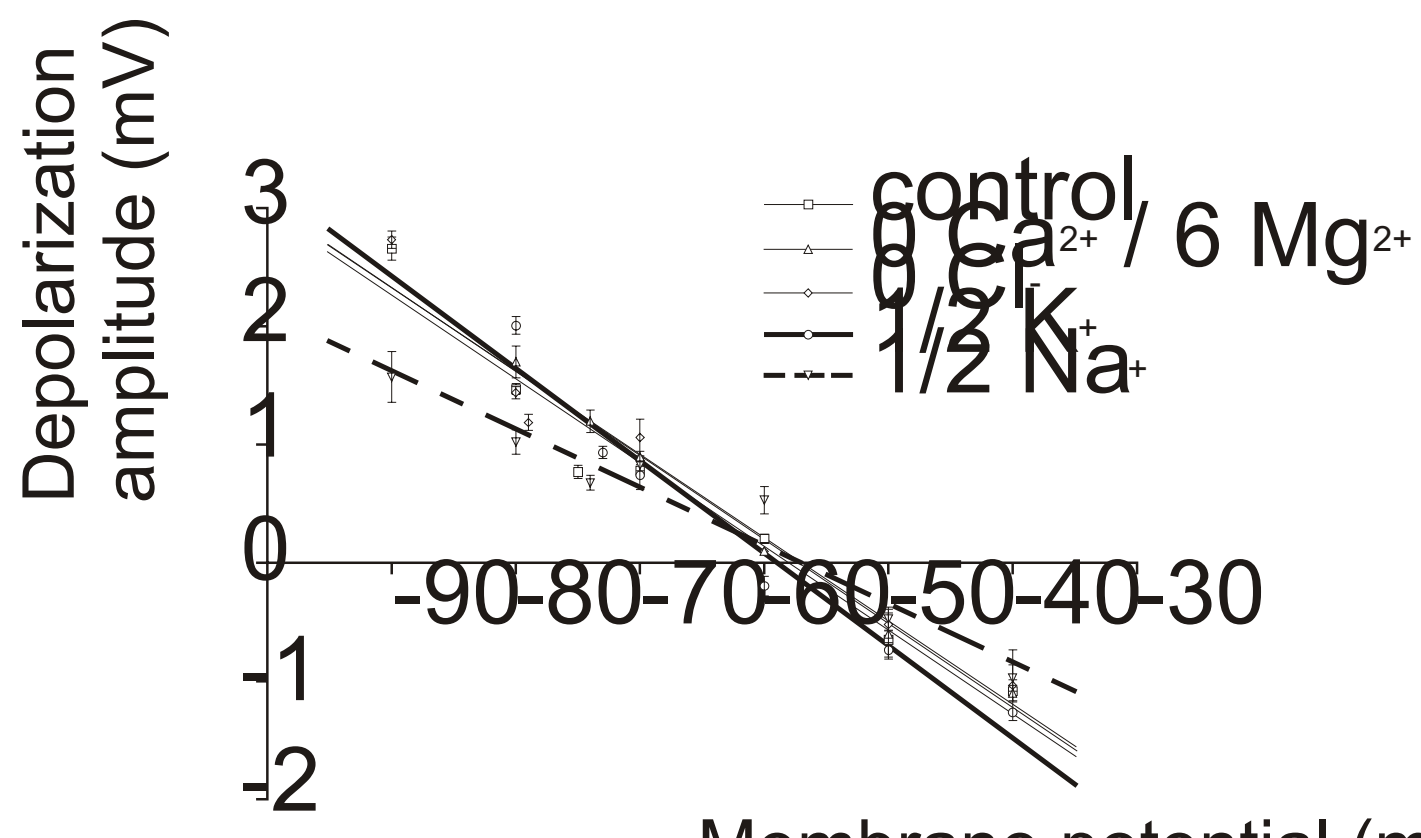

Membrane potential $(\mathrm{mV})$ 


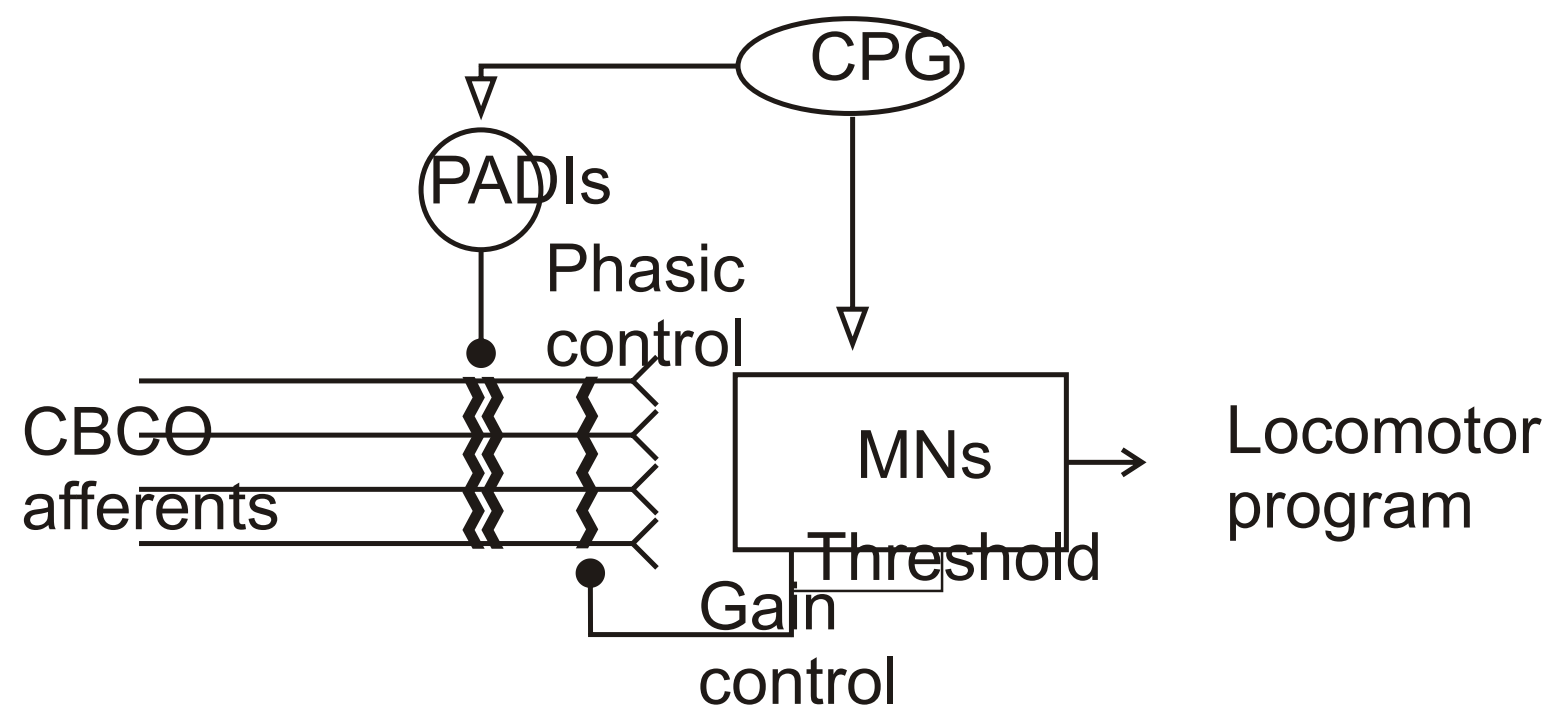

